\title{
Dynamics of Capillary Electrochromatography: Experimental Study of Flow and Transport in Particulate Beds
}

By

Guofang Chen, Martin Pačes, Miloš Marek, Yukui Zhang, Andreas Seidel-Morgenstern, and Ulrich Tallarek*

[*] Dr. rer. nat. U. Tallarek, Dipl.-Ing. Guofang Chen, Prof. Dr.-Ing. A. Seidel-Morgenstern Institut für Verfahrenstechnik der Otto-von-Guericke Universität Universitätsplatz 2, D-39106 Magdeburg (Germany)

Fax: $+49(0) 391-67-12028$

E-mail: ulrich.tallarek@vst.uni-magdeburg.de

Dipl.-Ing. M. Pačes, Prof. Dr.-Ing. M. Marek

Department of Chemical Engineering and Center for Nonlinear Dynamics of Chemical and Biological Systems

Prague Institute of Chemical Technology

Technická 5, CZ-16628 Prague (Czech Republic)

Prof. Dr. rer. nat. Y. Zhang

National Chromatography Research \& Analysis Center

Dalian Institute of Chemical Physics, Chinese Academy of Sciences

161 Zhongshan Road

Dalian 116011 (Peoples Republic of China) 


\begin{abstract}
The chromatographic performance with respect to the flow behaviour and dispersion in fixed beds of nonporous and macroporous particles (having mean intraparticle pore diameters of 41 $\mathrm{nm}, 105 \mathrm{~nm}$, and $232 \mathrm{~nm}$ ) has been studied in capillary HPLC and electrochromatography. The existence of substantial electroosmotic intraparticle pore flow (perfusive electroosmosis) in columns packed with the macroporous particles was found to reduce stagnant mobile mass transfer resistance and decrease the global flow inhomogeneity over the column cross-section, leading to a significant improvement in column efficiency compared to capillary HPLC. The effect of electroosmotic perfusion on axial dispersion was shown to depend sensitively on the mobile phase ionic strength and mean intraparticle pore diameter, thus, on an electrical double layer interaction within the particles. Complementary and consistent results were observed for the average electroosmotic flow through packed capillaries. It was found to depend on particle porosity and distinct contributions to the electrical double layer behaviour within and between particles. Based on these data an optimum chromatographic performance in view of speed and efficiency can be achieved by straightforward adjustment of the electrolyte concentration and characteristic intraparticle pore size.
\end{abstract}




\section{$1 \quad$ Introduction}

\subsection{Miniaturization in high performance liquid chromatography}

A miniaturization in high performance liquid chromatography (HPLC) concerning the column inner diameter (i.d.) and associated volumetric flow rates has been initiated more than 25 years ago [1-5], and it is an ongoing development mainly because of the need for handling small amount of complex sample. While the typical dimensions in analytical and narrow-bore HPLC include a 2.1-4.6 mm column i.d., bed lengths of less than $200 \mathrm{~mm}$ and random sphere packings of 5-15 $\mu \mathrm{m}$ average diameter particles, the further miniaturization towards nano-LC (Table 1) can offer distinct advantages [6-11] including the

i) reduced consumption of stationary phase, solvent and chemicals, facilitating a use of expensive stationary phase, exotic mobile phases and minute samples in the environmental and biomedical sciences,

ii) increased mass sensitivity due to a reduced chromatographic dilution,

iii) use of smaller, but still porous particles $\left(\mathrm{d}_{\mathrm{p}}=3-5 \mu \mathrm{m}\right)$ leading to higher column efficiencies by a significantly reduced contribution of the intraparticle stagnant zone to hydrodynamic dispersion,

iv) compatibility with flow rate requirements of a nano-ESI interface in view of an on-line coupling to mass spectrometry, and

v) application of high electrical fields for the additional (or exclusive) transport of bulk liquid and solute molecules through a porous medium by electroosmosis and/or electrophoresis.

Related to the last aspect, in general, mass transport in porous media induced by an externally applied electrical field nowadays plays a central role in a number of analytical, technological and environmental processes, including the dewatering of waste sludge and soil remediation, capillary electrophoresis or electrochromatographic separations in capillaries and microfluidic devices [12-28]. Still however, there exists a lack of mechanistic understanding concerning an interrelation between external control variables like the electrical field strength or current and parameters controlling macroscopic electrokinetic transport like the dispersion coefficient or effective mobility. It is intimately related to the physico-chemical nature of the surface and its dynamic behaviour, pore space morphology, and properties of the liquid. The characterization of these parameters is of a fundamental relevance as it critically guides the performance and 
compelling advantages, as well as design strategies of a particular electrokinetic process with respect to any alternative diffusive-convective transport schemes. In the present work we are concerned with the dynamics of electroosmotic flow (EOF) and solute transport in capillary electrochromatography (CEC). While the column efficiencies in HPLC may be increased by a reduction of the particle size this option is limited via the maximum operating pressure with conventional instrumentation. A significantly improved performance in view of the dispersion and permeability can be achieved in CEC by utilizing EOF for transport of bulk mobile phase. In this introduction we give a brief survey of some of the most important features of the EOF in porous media (like random sphere packings) because it may be a relatively unfamiliar topic to many readers. A hardware overview with a comparison of instrumental configurations used for generation and control of the required micro- and nanoliter volumes of liquid in capillary (electro)chromatography and nano-LC has been presented recently [11].

Table 1. Suggested nomenclature for different HPLC regimes [11].

\begin{tabular}{|c|c|c|c|}
\hline Category & $\begin{array}{c}\text { Column diameter } \\
\text { cross-sectional area) }\end{array}$ & Vol. flow rates & $\begin{array}{c}\text { Typical } \\
\text { loading }\end{array}$ \\
\hline Analytical HPLC & $5.0-3.9 \mathrm{~mm}\left(20-12 \mathrm{~mm}^{2}\right)$ & $5-1.5 \mathrm{ml} / \mathrm{min}$ & $2-10 \mathrm{mg}$ \\
\hline Narrow-bore HPLC & $3.9-2.1 \mathrm{~mm}\left(12-3.5 \mathrm{~mm}^{2}\right)$ & $1.5-0.2 \mathrm{ml} / \mathrm{min}$ & $0.5-2 \mathrm{mg}$ \\
\hline Micro HPLC & $2.1-0.5 \mathrm{~mm}\left(3.5-0.2 \mathrm{~mm}^{2}\right)$ & $300-10 \mu \mathrm{l} / \mathrm{min}$ & $50-500 \mu \mathrm{g}$ \\
\hline Capillary HPLC & $0.5-0.15 \mathrm{~mm}\left(0.2-0.02 \mathrm{~mm}^{2}\right)$ & $15-1 \mu \mathrm{l} / \mathrm{min}$ & $1-50 \mu \mathrm{g}$ \\
\hline Nano(scale) LC & $<0.15 \mathrm{~mm}\left(<0.02 \mathrm{~mm}^{2}\right)$ & $<1 \mu \mathrm{l} / \mathrm{min}$ & $<1 \mu \mathrm{g}$ \\
\hline
\end{tabular}

\subsection{Capillary electrochromatography}

CEC is a relatively new separation technique carried out most commonly in a capillary column packed with conventional HPLC adsorbent material by utilizing an electroosmotically driven mobile phase at high electrical field strength $(50-100 \mathrm{kV} / \mathrm{m})$ in an apparatus similar to that used in capillary zone electrophoresis (CZE). Consequently, CEC combines the variety of retention mechanisms and stationary phase selectivities popular in HPLC with miniaturization potential of CZE. Tsuda [29] described electrochromatography as an electrophoretic analysis where sorptive interactions with the stationary (retentive) phase of the support material are a major contribution, i.e., the separation is achieved by a differential partitioning and migration. 
Although the origin of CEC traces back to 1974 when Pretorius et al. [30] have reported the successful electrokinetic transport of eluent through a (comparatively large) chromatographic column, it has been Jorgenson and Lukacs [31] who demonstrated the feasibility of CEC for a separation of neutral compounds by applying a potential gradient across a packed column of capillary dimension, before Knox and Grant [32-34] examined more fundamental aspects and the advantages of CEC.

\subsubsection{Advantages of CEC over capillary HPLC}

CEC is commonly performed in a 50-150 $\mu \mathrm{m}$ i.d. (fused-silica) capillary column setup which is usually composed of a packed bed and open tubular segment, as well as a detection window immediately behind the outlet frit of the fixed bed. Compared to pressure-driven flow a superior performance of EOF through a single, straight and open capillary originates from the fact that in the limit of a thin electrical double layer (EDL) the velocity apparently slips at the inner wall of the capillary and, thus, the fluid moves as in plug-flow (assuming isothermal conditions) [35-38]. Further, for fixed pressure and potential gradients, the ratio of volumetric EOF to hydraulic flow rates is inversely proportional to the square of the capillary radius [39]. The flat "pore-level" velocity profile of EOF observed for a single-pore geometry (as in CZE) $[40,41]$ and permeability criterion also have important implications for the fluid dynamics (an improved dispersion behaviour, in particular) in CEC where many pores are connected, as in a random particulate fixed bed, including

i) a use of micron- and submicron-sized particles as packing material [42, 43] for reduction of band spreading toward the diffusion-limited regime,

ii) the operation of relatively long packed columns (if needed) or, vice versa, use of very short chromatographic beds [44],

iii) further reduction of the column diameter toward chip format [45-49],

iv) the generation of a substantial EOF within the porous particles (electroosmotic perfusion) which reduces intraparticle mass transfer resistance and associated holdup dispersion [50-55],

v) a higher separation efficiency based on the superior hydrodynamic dispersion characteristics (cf. Figure 1) in the interstitial pore space of a sphere packing over a wide range of experimental conditions [34], and

vi) the enhancement of intraparticle transport of charged species by migration and surface (electro)diffusion [56, 57]. 
Thus, CEC offers the potential for an implementation into miniaturized systems allowing high sample throughput and resolution, speed and sensitivity. Compared to liquid chromatography CEC offers a better permeability and efficiency, as well as selectivity (in the case of charged analytes), and concerning CZE it operates in systems with far higher surface-to-volume ratio in view of sample capacity and dynamic changes in surface properties. As in capillary HPLC the actual flow rates are inherently compatible with direct mass spectrometric detection.
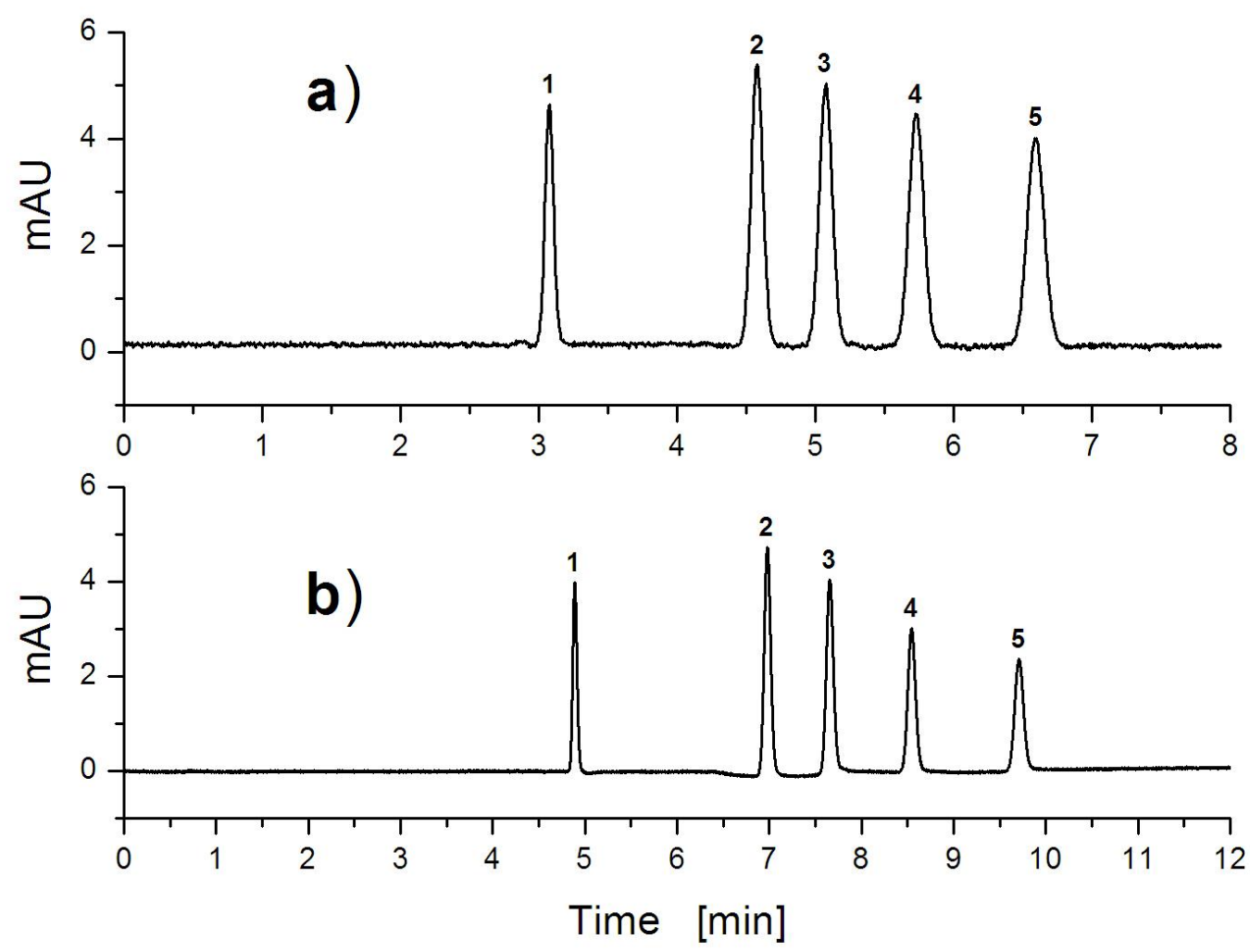

Figure 1. Separation efficiency at similar mobile phase average velocity. a) Capillary HPLC, packed bed of $150 \mathrm{~mm}$ length in a $100 \mu \mathrm{m}$ i.d. capillary, in-column detection $(215 \mathrm{~nm})$; analytes: (1) thiourea, (2) methylbenzoate, (3) ethylbenzoate, (4) propylbenzoate, and (5) butylbenzoate. b) CEC, $325 \mathrm{~mm}$ long capillary setup (effective packed bed length of $240 \mathrm{~mm}$ ) x $100 \mu \mathrm{m}$ i.d., applied voltage: $20 \mathrm{kV}$. Stationary phase: Porous C18-silica particles $\left(d_{p}=2.45 \mu \mathrm{m}\right.$ and $\left.d_{\text {pore }}=14 \mathrm{~nm}\right)$. The mobile phase is a $5 \mathrm{mM}$ aqueous Tris ( $\mathrm{pH}-8.3) /$ acetonitrile 20:80 (v/v) buffer solution. The separation efficiency in CEC is about $2 \times 10^{4} \mathrm{~N} / \mathrm{m}$.

As demonstrated by Figure 1 the separation efficiency in CEC is about twice as high as that in HPLC when using particles with a pore size $\left(\mathrm{d}_{\text {pore }} \approx 10 \mathrm{~nm}\right)$ of the order of the EDL thickness of typically 1-10 $\mathrm{nm}$. We see below how this improvement can still be substantially increased by optimizing intraparticle EOF with macroporous particles $\left(d_{\text {pore }}>30 \mathrm{~nm}\right)$. 


\subsubsection{EOF in a fixed bed of spherical particles}

\subsubsection{Simple considerations}

Let us consider a random-close packing of spherical-shaped, solid and dielectric (i.e., impermeable and nonconducting) particles with a uniform distribution of the electrokinetic or shear-plane potential $\left(\zeta_{\mathrm{p}}\right)$ at their external surface and an EDL thickness (typically represented by the Debye screening length $\left.\lambda_{\mathrm{D}}\right)$ much smaller than the particle radius $\left(\mathrm{r}_{\mathrm{p}}\right)$. In this thin EDL limit $\left(\mathrm{r}_{\mathrm{p}} / \lambda_{\mathrm{D}} \gg 1\right)$ the macroscopic, average EOF velocity $\left\langle\mathbf{u}_{\mathrm{p}}\right\rangle$ through a column of volume $\mathrm{V}_{\mathrm{c}}$ is obtained by integration over the interparticle bed volume $\mathrm{V}_{\text {inter }}$ [58]

$$
\left\langle\mathbf{u}_{\mathrm{p}}\right\rangle=\frac{1}{\mathrm{~V}_{\mathrm{c}}} \int_{\mathrm{V}_{\text {inter }}} \mathbf{u}_{\mathrm{p}} \mathrm{dV} \mathrm{V}_{\mathrm{c}}=-\frac{\varepsilon_{0} \varepsilon_{\mathrm{r}} \zeta_{\mathrm{p}}}{\eta_{\mathrm{f}} \mathrm{V}_{\mathrm{c}}} \int_{\mathrm{V}_{\text {inter }}} \mathbf{E} \mathrm{dV} \mathrm{V}_{\mathrm{c}},
$$

where $\varepsilon_{0}, \varepsilon_{\mathrm{r}}$ and $\eta_{\mathrm{f}}$ are the permittivity of vacuum, and the relative permittivity and viscosity of the electrolyte solution, respectively. $\mathbf{u}_{\mathrm{p}}$ is the local slip velocity along the particles surface just outside the thin EDL which results from the lines of force (in the EDL) due to interaction of the electrical field of local strength $\mathbf{E}=-\nabla \Phi$ with a locally charged fluid $[59,60]$

$$
\mathbf{u}_{\mathrm{p}}=-\frac{\varepsilon_{0} \varepsilon_{\mathrm{r}} \zeta_{\mathrm{p}} \mathbf{E}}{\eta_{\mathrm{f}}} .
$$

Because the incompressible flows of electricity and fluid are parallel and proportional to each other at the solid-liquid interface, Eq. 2 is supposed to hold also throughout the whole liquid phase [60]. Although the no-slip condition is usually assumed for the fluid adjoining a surface [61], i.e., the velocity rises from zero at the shear plane to a limiting value beyond the EDL, it seems to slip past the surface from a macroscopic point of view. $\lambda_{\mathrm{D}}$ is given by

$$
\lambda_{\mathrm{D}}=\left(\frac{\varepsilon_{0} \varepsilon_{\mathrm{r}} \mathrm{RT}}{\mathrm{F}^{2} \sum_{\mathrm{i}} \mathrm{z}_{\mathrm{i}}^{2} \mathrm{c}_{\mathrm{i}, \infty}}\right)^{1 / 2},
$$

where $\mathrm{R}$ is the gas constant, $\mathrm{T}$ absolute temperature and F Faraday's constant, $\mathrm{z}_{\mathrm{i}}$ is the valency of ionic species $i$ and $c_{i, \infty}$ its molar concentration in the electroneutral solution (that is, beyond the EDL). For the macroscopic electrical current density we have 


$$
\left\langle\mathbf{i}_{\mathrm{el}}\right\rangle=\mathrm{K} *\langle\mathbf{E}\rangle=\frac{\mathrm{K}^{\infty}}{\mathrm{V}_{\mathrm{c}}} \int_{\mathrm{V}_{\text {inter }}} \mathbf{E} \mathrm{dV} \mathrm{V}_{\mathrm{c}}=\frac{\mathrm{K}^{\infty}}{\mathrm{V}_{\mathrm{c}}} \int_{\mathrm{V}_{\text {inter }}} \frac{\mathbf{i}_{\mathrm{el}}}{\mathrm{K}^{\infty}} \mathrm{dV}_{\mathrm{c}},
$$

where $\mathrm{K}^{\infty}$ is the conductivity of the equilibrium electrolyte beyond the EDL and $\mathrm{K}^{*}$ stands for the conductivity of the packed column. By combining Eqs. 1 and 4 we obtain

$$
\left\langle\mathbf{u}_{\mathrm{p}}\right\rangle=-\frac{\varepsilon_{0} \varepsilon_{\mathrm{r}} \zeta_{\mathrm{p}}\left\langle\mathbf{i}_{\mathrm{el}}\right\rangle}{\eta_{\mathrm{f}} \mathrm{K}^{\infty}}=-\frac{\varepsilon_{0} \varepsilon_{\mathrm{r}} \zeta_{\mathrm{p}}\langle\mathbf{E}\rangle}{\eta_{\mathrm{f}}}\left(\frac{\mathrm{K}^{*}}{\mathrm{~K}^{\infty}}\right) .
$$

Thus, the EOF velocity averaged over the column cross-section can be expressed by means of the conductivity ratio $\mathrm{K}^{*} / \mathrm{K}^{\infty}$ which becomes accessible experimentally via conductivities of a packed column and an identical, but open tube saturated with the same electrolyte solution. It is further assumed that the EDL only makes a negligible contribution to the total conductivity of the sphere packing [62,63]. The above considerations are valid for beds of nonporous (and porous) particles with arbitrary shape and size distribution.

\subsubsection{Electrokinetic wall effect}

Typically, CEC is carried out in a cylindrical capillary column of $\mathrm{d}_{\mathrm{c}} \leq 150 \mu \mathrm{m}$ packed with $d_{p}=3-10 \mu \mathrm{m}$ porous adsorbent particles. Electrical fields of up to $100 \mathrm{kV} / \mathrm{m}$ are applied to move a buffer solution and solute molecules through the porous medium by electroosmosis (and electrophoresis, if analytes were charged) $[18,64]$. Thus, we have $d_{c} / d_{p} \leq 50$, with aspect ratios between 20 and 30 being most common. In this range the presence of a column wall has several consequences for macroscopic flow and transport.

First, the radial porosity distribution is systematically influenced over a substantial volume of the column. Concerning the packing density close to the wall it has been shown that the radial distribution of voidage in a random sphere packing is inhomogeneous [65-68], and that the interstitial porosity ( $\left.\varepsilon_{\text {inter }}\right)$ starts with a maximum value of unity at the column inner wall, then displays damped oscillations with a period close to $d_{p}$ over a distance of about 4-5 $d_{p}$ into the bulk of the bed, before reaching void fractions typical for bulk packing $\left(\varepsilon_{\text {inter }}=0.38-0.4\right)$. This geometrical wall effect can be explained by the decrease of packing order as the distance from the wall increases and may have a strong impact on the macroscopic flow heterogeneity, axial 
dispersion, and particle-to-fluid heat and mass transfer, especially at aspect ratios $d_{c} / d_{p}$ below 15 [69-74] when this critical wall region occupies a substantial fraction of the column. Since radial variations of transport properties have a far more serious effect on column performance than axial ones, this packing aspect will be quite important for capillary HPLC, but may have less impact on a macroscopic velocity inequality of the flow pattern in CEC. In close relation, it has been demonstrated that in the thin EDL limit the average EOF velocity in a single pore is relatively independent of pore radius [35] which, on a macroscopic scale, is complemented by observing that average EOF in packed capillaries then is hardly influenced by the particle diameter [34].

Rather than a radial porosity distribution, it is the radial distribution of electrokinetic potential $(\zeta)$ at the solid-liquid interface which determines the EOF profile in a fixed bed. In addition to EOF generated locally at the particles surface $\left(\zeta_{\mathrm{p}}\right)$ we also have to consider the capillary inner wall as a source for EOF $\left(\zeta_{\mathrm{w}}\right)$. In general, the electrokinetic (and chromatographic) properties of these surfaces can be very different. This fact introduces an electrokinetic wall effect which depends on the aspect ratio $\left(\mathrm{d}_{\mathrm{c}} / \mathrm{d}_{\mathrm{p}}\right)$ and actual potential mismatch $\left(\zeta_{\mathrm{w}} / \zeta_{\mathrm{p}}\right)$ as depicted in Figure 2. The influence of a charged capillary inner wall on the radial distribution of EOF velocities may be estimated by $[58,75]$

$$
\frac{\mathrm{u}(\mathrm{r})}{\mathrm{u}_{\mathrm{p}}}=1+\left(\frac{\zeta_{\mathrm{w}}}{\zeta_{\mathrm{p}}}-1\right) \frac{\mathrm{I}_{0}\left(\beta \mathrm{r} / \mathrm{d}_{\mathrm{p}}\right)}{\mathrm{I}_{0}\left(\beta \mathrm{r}_{\text {eff }} / \mathrm{d}_{\mathrm{p}}\right)} \quad \text { for } 0 \leq \mathrm{r} \leq \mathrm{r}_{\mathrm{c}}-7 \lambda_{\mathrm{D}} \cong \mathrm{r}_{\text {eff }}
$$

where $I_{0}$ is the zero-order modified Bessel function of the first kind, $r_{\text {eff }}$ an effective capillary radius accounting for the no-slip condition at the inner wall of the column, and $\beta$ characterizes the overall permeability of a bed [76]

$$
\beta=3 \sqrt{\frac{\alpha\left(1-\varepsilon_{\mathrm{bed}}\right)}{2}}
$$

The dimensionless parameter $\alpha$ depends on the drag force provided by a particle and, thus, on packing structure, particle shape and permeability. Based on Eq. 6, Figure 2 demonstrates the strong effect of $\zeta_{\mathrm{w}} / \zeta_{\mathrm{p}}$ on the resulting trans-column EOF profiles. The wall effect in CEC is limited to a relatively narrow annulus at the wall that inreases in width with the magnitude of the excess zeta-potential $\zeta_{\mathrm{ex}}=\zeta_{\mathrm{w}}-\zeta_{\mathrm{p}}$. 


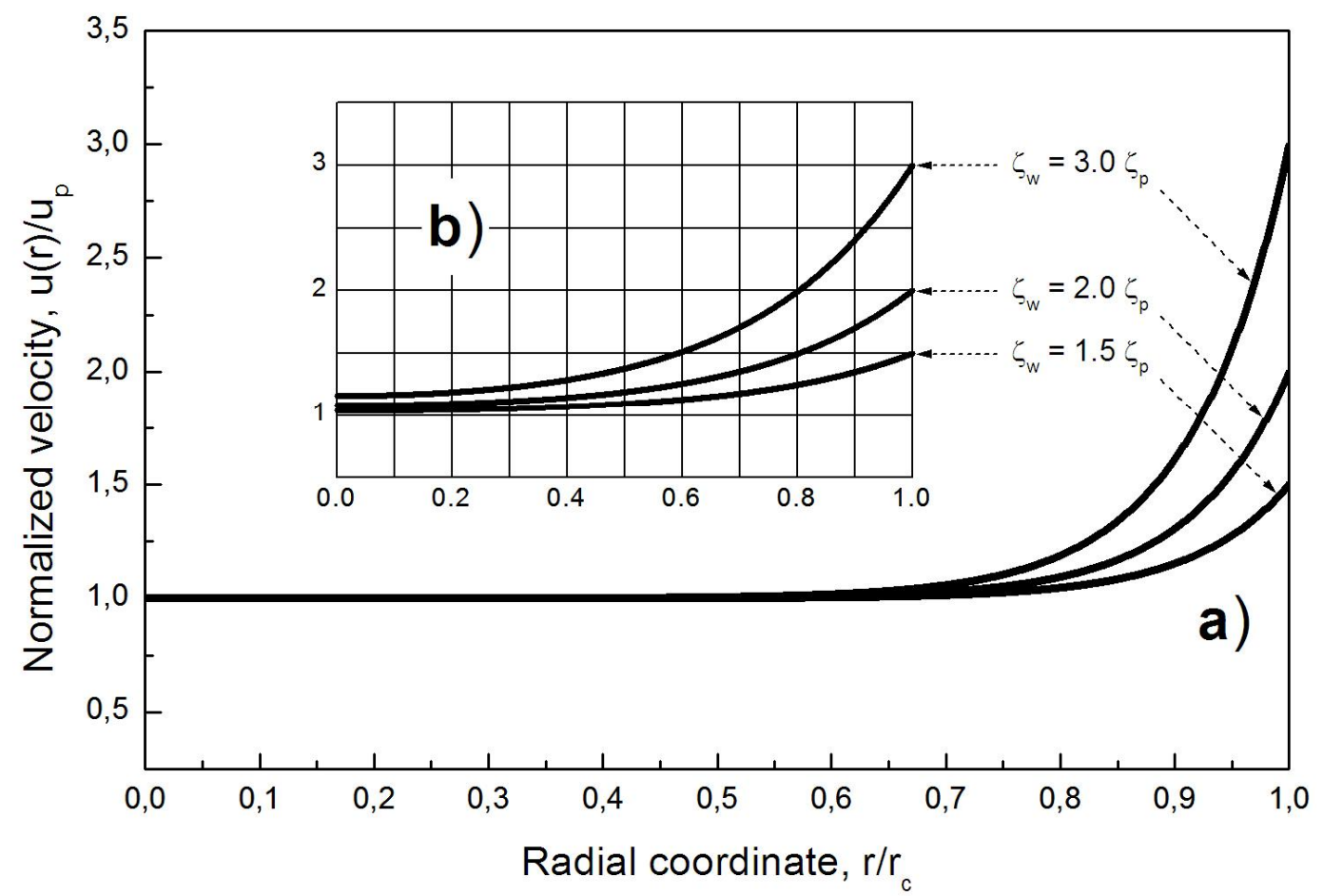

Figure 2. Prediction of radial EOF distributions normalized by $\mathrm{u}_{\mathrm{p}}$ (the velocity generated locally at the external particle surface) in a sphere packing for different values of $\zeta_{w} / \zeta_{p}$ and aspect ratios as based on Eq. 6 with $\mathrm{r}_{\mathrm{c}}=125 \mu \mathrm{m}, \lambda_{\mathrm{D}}=3.9 \mathrm{~nm}$, and $\beta=1.65$ [80]. a) $\mathrm{d}_{\mathrm{c}} / \mathrm{d}_{\mathrm{p}}=15$ and b) $\mathrm{d}_{\mathrm{c}} / \mathrm{d}_{\mathrm{p}}=5$.

Although the particles surface and capillary inner wall typically both carry a negative charge density, the open fused-silica capillaries are known to give EOF velocities significantly higher than those of many packing materials in CEC [77-79]. The electrokinetic wall effect recently has been spatially resolved by dynamic NMR microscopy with $40 \mu \mathrm{m}$ in-plane resolution in a study of flow through a $250 \mu \mathrm{m}$ i.d. fused-silica capillary packed with $50 \mu \mathrm{m}$ cation exchange particles [80]. This work has clearly demonstrated that a significantly higher velocity close to the wall than in the center of the column affects transient hydrodynamic dispersion, leading to a long-time disequilibrium in the fluid molecules axial displacement probability distribution. Thus, the electrokinetic wall effect is too significant to neglect in current CEC practice with $\mathrm{d}_{\mathrm{c}} / \mathrm{d}_{\mathrm{p}} \leq 30$ (unless $\zeta_{\mathrm{w}} \approx \zeta_{\mathrm{p}}$ ). 


\subsubsection{Electroosmotic perfusive flow}

The general tendency towards the use of submicron-size particles in chromatography is based on the popular models of, e.g., van Deemter et al. [81], Giddings [82], or Kennedy and Knox [83] for dispersion in packed columns which predict a lower height equivalent to a theoretical plate (HETP) at the same linear velocity and, thus, higher separation efficiency as the particle size is reduced. An alternative to nanoparticles (which are difficult to pack in form of stable and sufficiently long beds) in capillary HPLC and CEC is the utilization of pore flow within much larger, but macro- or even gigaporous particles. Perfusion chromatography refers to separation processes with non-zero intraparticle velocity and has received much attention in the past [84-92]. However, signifcant mobile phase perfusion in beds of permeable particles is realized with hydraulic flow only when high column pressure drops and particles with large (giga)pores are encountered which limits the intraparticle surface-to-volume ratio in view of a particles mechanical strength or adsorption capacity. But even then, the intraparticle velocities remain small compared to velocities in the interparticle pore space and they are relevant only for the transport of slowly diffusing (bio)molecules [93-95].

The hierarchical design of wide-pore material has been an important aspect from the particle engineering point of view [96, 97]. As illustrated in Figure 3 hierarchically-structured spheres are made by inter-adhering primary particles in several clustering steps. The resulting particle can have two sets of pores, the large gigapores with $d_{\text {pore }} / d_{p}>10^{-2}[90]$ and macropores. More important even, hierarchical design produces a good correlation of interconnectivity between these discrete sets of pores and minimizes any dead-end branching. The gigapores transect the particle as a whole (Figure 3) and are the only basis for the still small intraparticle convection in hydraulic flow. By contrast, even the macropores are large enough for allowing substantial intraparticle EOF by an adjustment of the mobile phase ionic strength to the pore dimensions such that $r_{\text {pore }} / \lambda_{D} \gg 1$ or that, at least, $r_{\text {pore }} / \lambda_{D}>1$ is guaranteed [50-55].

Thus, due to the strikingly different possibilities for tuning experimentally electroosmotic and hydraulic permeabilities of the packed bed, an important performance advantage of CEC over capillary HPLC lies in the new dimension of the perfusion mechanism. It has been shown that electroosmotic perfusion through fixed beds of porous particles proceeds with a significantly higher intraparticle permeability $[55,98,99]$ and that, compared with hydraulic flow, the EOF offers a far superior dispersion characteristics [50-53]. Gigapores are definitely not needed for electroosmotic perfusion, and the pore space morphology rather should be optimized in view 
of the surface-to-volume ratio while maintaining substantial intraparticle EOF at modest ionic strength. As these considerations point toward a macropore domain we studied systematically the influence of intraparticle EDL overlap on flow and dispersion in random sphere packings by using macroporous $\mathrm{C} 18$-silica particles with almost identical mean particle diameter and a monomodal pore size distribution, but with different mean intraparticle pore sizes. Thus, EDL overlap could be complementary adjusted by changing either mobile phase ionic strengths or the particles pore size.
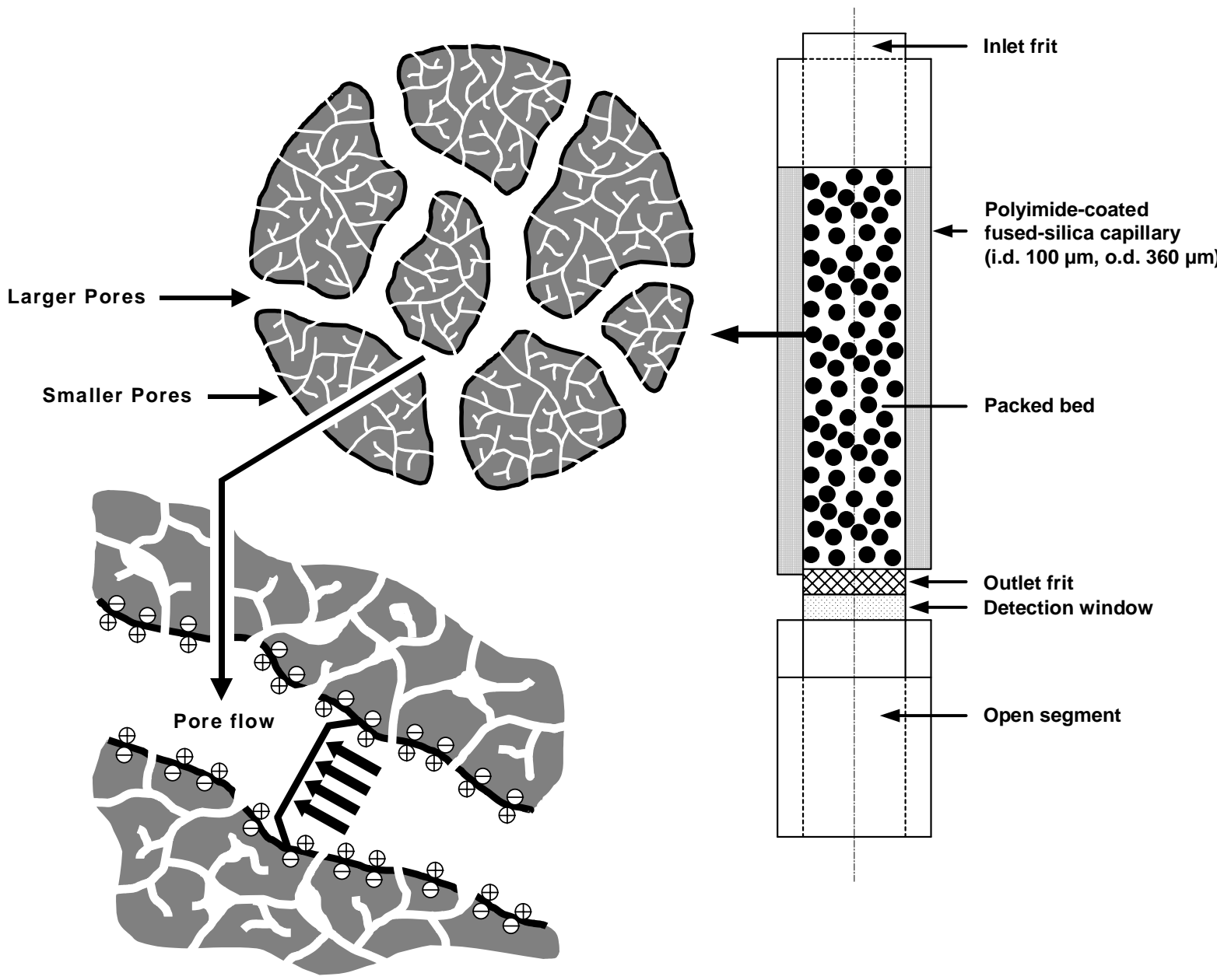

Figure 3. Column configuration representative for CEC and capillary HPLC with typical parameters $\left(L_{\text {bed }} / d_{c}>1000, d_{d} / d_{p}=10-50, d_{p} / d_{\text {pore }}>100\right.$, and $\left.d_{\text {pore }} / \lambda_{D}=5-50\right)$, and the pore space morphology of a hierarchically-structured particle with bimodal pore size distribution [53]. 


\section{Experimental section}

\subsection{Characterization of the silica-based particles}

Physical data of the (non)porous, spherical-shaped C18-silica particles are summarized in Table 2. While all particles have almost the same averaged diameter, the mean intraparticle pore size is different. Thus, at a given column diameter $\left(d_{c}\right)$ the aspect ratio $d_{c} / d_{p}$ was constant for all packings which allowed to address systematically the influence of an intraparticle EDL overlap on EOF behaviour (electroosmotic perfusion) and associated dispersion in fixed beds without conflicting contribution from the electrokinetic wall effect (which depends on $d_{c} / d_{p}$ ). Further, at the aspect ratio realized in the experiments $\left(d_{c} / d_{p}=40\right)$ this wall effect is expected to play a less significant role anyway. Particles were received from Merck KGaA (Darmstadt, Germany), together with the mercury intrusion and nitrogen adsorption data needed for the determination of pore volume and surface area, respectively. Table 2 indicates that a particles surface-to-volume ratio decreases significantly while its mean pore diameter is increased. Size distributions were analyzed with a 1180 laser particle size analyzer from CILAS (Marcoussis, France) using dilute suspensions in isopropanol. All macroporous particles have a monomodal intraparticle pore size distribution.

Table 2. Physical data for the (non)porous silica-based particles.

\begin{tabular}{|c|c|c|c|c|c|c|}
\hline Particles & $\mathrm{d}_{\mathrm{p}}[\mu \mathrm{m}]^{\mathrm{a})}$ & $\mathrm{V}_{\text {pore }}[\mathrm{ml} / \mathrm{g}]$ & $\mathrm{d}_{\text {pore }}[\mathrm{nm}]^{\mathrm{b})}$ & $\varepsilon_{\text {intra }}^{c)}$ & $\mathrm{r}_{\mathrm{pore}} / \lambda_{\mathrm{D}}^{\mathrm{d})}$ & $\mathrm{A}_{\mathrm{s}}\left[\mathrm{m}^{2} / \mathrm{g}\right]^{\mathrm{e})}$ \\
\hline \multirow{3}{*}{ Porous spheres } & 2.45 & 0.88 & 41 & 0.66 & $0.6-12.8$ & 64.7 \\
\hline & 2.46 & 0.65 & 105 & 0.59 & $1.6-32.8$ & 21.1 \\
\hline & 2.42 & 0.34 & 232 & 0.43 & $3.6-72.5$ & 7.5 \\
\hline Nonporous & 2.45 & \multicolumn{4}{|c|}{-} & ca. 1 \\
\hline
\end{tabular}

\footnotetext{
a) Refers to the external surface-averaged value.

b) Mean intraparticle pore diameter based on mercury porosimetry.

${ }^{\text {c) }} \varepsilon_{\text {intra }}=\left(1+\left(1 / \rho_{\mathrm{SiO}} \mathrm{V}_{\text {pore }}\right)\right)^{-1}$, with $\rho_{\mathrm{SiO}}$ taken as $2.24 \mathrm{~g} / \mathrm{ml}$.

${ }^{\mathrm{d})}$ For buffer concentrations used in this work ( $1 \times 10^{-4}$ to $4 \times 10^{-2} \mathrm{M}$ Tris).

e) Specific surface area based on nitrogen adsorption.
} 


\subsection{Column packing procedure}

The setup used for the packing procedure is shown in Figure 4. Fused-silica capillaries with $100 \mu \mathrm{m}$ i.d. and $360 \mu$ m o.d. (Polymicro Technologies, Phonenix, AZ) were packed by a slurry packing method [100] using a WellChrom K-1900 pneumatic pump (KNAUER GmbH, Berlin, Germany). As the slurry reservoir $500 \mu \mathrm{m}$ i.d. glass-lined metal tubing has been used. MicroTight zero-dead-volume unions (including the fittings and gauge-plug) with MicroTight tubing sleeve, inlined with a glass-fibre filter providing a temporary outlet frit during packing were obtained from Upchurch Scientific (Oak Harbor, WA, USA). An SSI two-way valve and SSI (dual-stem) three-way valve (ERC, Riemerling, Germany) between pneumatic pump and slurry reservoir were used for pressure release and slurry injection, respectively. Slurries were prepared by suspending $10 \mathrm{mg}$ of the dry particles in $100 \mu \mathrm{l}$ ethanol under ultrasonication for $15 \mathrm{~min}$. The slurry reservoir was filled with a syringe. Subsequently, using water as a pushing fluid, particles were forced into the fused-silica capillary at set pressure. During the packing process the capillary (and optionally also the slurry reservoir) was placed in an ultrasonic bath to compact and stabilize the beds which reached a length of at least $300 \mathrm{~mm}$ within $5-10 \mathrm{~min}$. Finally, the pump was switched off, the pressure allowed to release, and the bed inspected for uniformity under a microscope.

Then, the packed capillary was flushed with water again for $45 \mathrm{~min}$. At a little higher pressure than used for the packing, permanent inlet and outlet frits of a bed were made by sintering the silica particles for $350 \mathrm{~ms}$ with an arc fusion splicer FSM-05S (Fujikura Tokyo, Japan) in its prefusion mode. Pressure was released to $200 \mathrm{bar}$, the MicroTight union disconnected from the column, and the remainder of particles flushed out with water. The detection window was prepared by scraping off some of the polyimide-coating $2 \mathrm{~mm}$ immediately downstream from the outlet frit. Protocols for column packing and frit sintering were optimized with respect to the pore-sizes of a material in order to produce packed beds of uncrushed wide-pore particles. For example, a packing pressure of 350, 300, and 250 bar was selected for the particles with 40, 120, and $220 \mathrm{~nm}$ mean pore size, respectively, while for the nonporous silica particles 400 bar were used. Packed columns were preconditioned electrokinetically by applying a voltage of $5 \mathrm{kV}$ for $5 \mathrm{~min}$, a voltage ramp up to $20 \mathrm{kV}$ within $20 \mathrm{~min}$, and a constant voltage of $20 \mathrm{kV}$ for another $20 \mathrm{~min}$. When changing between mobile phases, capillaries were also conditioned electrokinetically by applying a voltage ramp up to $20 \mathrm{kV}$ within $20 \mathrm{~min}$ and constant voltage of $20 \mathrm{kV}$ for another $20 \mathrm{~min}$. 


\subsection{Hardware configuration}

CEC experiments at controlled temperature of $298 \mathrm{~K}$ with electrical potential gradients between both ends of a capillary setup of up to $30 \mathrm{kV}$ were performed in a $\mathrm{HP}^{3 \mathrm{D}} \mathrm{CE}$ capillary instrument (Hewlett-Packard, Waldbronn, Germany) equipped with a diode array detector that was operated at $215 \mathrm{~nm}$. An external helium pressure of 10 bar was applied on inlet and outlet mobile phase vials for minimizing bubble formation. Samples were injected electrokinetically ( $3 \mathrm{kV}$ for $3 \mathrm{~s}$ ). EOF velocities were calculated using the actual potential drop over the bed and residence time distributions of an unretained, uncharged flow field marker (thiourea) which is transported through the column by molecular diffusion and the EOF. HPLC experiments were carried out using a capillary liquid chromatography setup containing the MicroPro ${ }^{\mathrm{TM}}$ syringe pumping system (Eldex Laboratories Inc., Napa, CA) and a SpectraFlow 501 UV/Vis detector (SunChrom, Friedrichsdorf, Germany) operated at $215 \mathrm{~nm}$. This pump allows practicable flow rates from $200 \mu \mathrm{l} / \mathrm{min}$ down to $10 \mathrm{nl} / \mathrm{min}$ in isocratic and down to $1 \mu \mathrm{l} / \mathrm{min}$ in gradient elution mode without split. Mixing is provided by a ( $85 \mu 1$ or $15 \mu \mathrm{l})$ dynamic mixer or, for the lower microliter flow rates, by $(\leq 5 \mu \mathrm{l})$ static mixers [11].

\subsection{Mobile phase composition}

Tris(hydroxymethyl)aminomethane (Tris) buffer solutions in 80:20 acetonitrile/water (v/v) were used as the liquid electrolyte. Mobile phases generally were filtered over a $0.45 \mu \mathrm{m}$ nylon membrane filter and degassed by ultrasonication. An aqueous stock solution of $0.2 \mathrm{M}$ Tris (base form) was prepared using water purified on a Milli-Q-Gradient (Millipore GmbH, Eschborn, Germany). The $\mathrm{pH}$ was adjusted to 8.3 by titration with concentrated hydrochloric acid. Appropriate volumes of this stock solution, MilliQ water, and HPLC grade acetonitrile were mixed to yield Tris buffer solutions of desired ionic strength in 80:20 acetonitrile/water (v/v) covering the range from $1 \times 10^{-4}$ to $4 \times 10^{-2} \mathrm{M}$ effective Tris concentration, e.g., $2 \times 10^{-3}$ $\mathrm{M}$ Tris in a final electrolyte corresponds to $0.01 \mathrm{M}$ Tris in the aqueous part. The concentration of protonated Tris (acid form) needed for estimating the EDL thickness by means of $\lambda_{\mathrm{D}}$ (Eq. 3) was calculated from the Henderson-Hasselbalch equation in which $\mathrm{pH} \approx \mathrm{pK}_{\mathrm{a}}$. The relative permittivity $\left(\varepsilon_{\mathrm{r}}\right)$ and viscosity $\left(\eta_{\mathrm{f}}\right)$ at $298 \mathrm{~K}$ of the final mobile phases were taken as 44.53 and $5.03 \times 10^{-4} \mathrm{kgm}^{-1} \mathrm{~s}^{-1}$, respectively [101]. When needed, the mobile phase diffusivity $\left(\mathrm{D}_{\mathrm{m}}\right)$ of an analyte was calculated according to the Wilke-Chang equation [102]. 


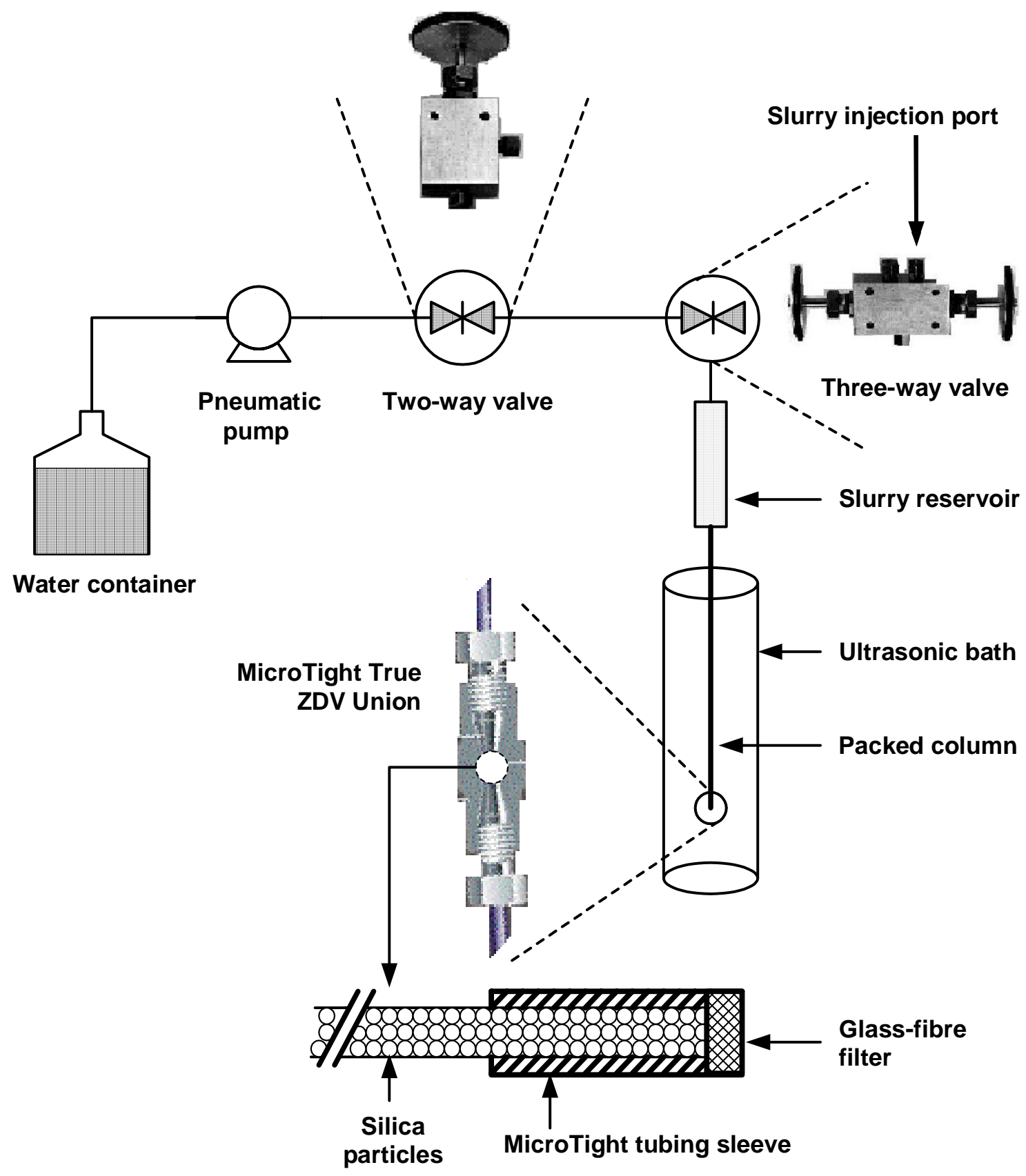

Figure 4. Schematics of the experimental setup implemented for packing the cylindrical (fused-silica) capillary columns with particulate stationary phase material. 


\subsection{Sample properties}

Thiourea, tris(hydroxymethyl)aminomethane (Tris) and hydrochloric acid of analytical grade, as well as HPLC grade acetonitrile were purchased from Fluka (Sigma-Aldrich Chemie GmbH, Taufkirchen, Germany). The alkylbenzoates all came from Merck KGaA (Darmstadt, Germany). Under the conditions encountered in this work the analyte concentration remained within the linear range of the adsorption isotherm and, generally, the sample was prepared in running mobile phase. Only a few experimental studies of preparative electrochromatographic separations have been published yet [103-106]. Uncharged analytes were selected because the transport behaviour of a charged molecule would be complicated further by its electrophoretic migration and possible effects originating from a coupling of the charge adsorption with the local electrokinetics [107]. This issue becomes even more complex when analyte and surface groups (relevant for EOF) are involved in $\mathrm{pH}-$ dependent equilibria [108]. 


\section{$3 \quad$ Results and discussion}

\subsection{Influence of intraparticle pore size on separation efficiency}

The equilibrium-dispersive model of chromatography [102] assumes that mobile and stationary phases are constantly in equilibrium, and that contributions to dispersion including kinetic effects like mass transfer resistances and a finite adsorption-desorption kinetics can be lumped together in an apparent axial dispersion coefficient $\left(\mathrm{D}_{\mathrm{ax}}\right)$. Then, from the variance of a Gaussian peak in linear chromatography $\mathrm{D}_{\mathrm{ax}}$ is calculated by

$$
\mathrm{D}_{\mathrm{ax}}=\frac{\mathrm{Hu}_{\mathrm{av}}}{2}=\frac{\mathrm{L}_{\mathrm{bed}} \mathrm{u}_{\mathrm{av}}}{2 \mathrm{~N}} .
$$

The effect of mean intraparticle pore size on the separation efficiency in CEC was studied by monitoring the axial dispersivity $\mathrm{D}_{\mathrm{ax}} / \mathrm{D}_{\mathrm{m}}$ in dependence of the particle Peclet number Pe for C18-silica particles with a different mean pore diameter (Table 2). Figure 5 shows that $D_{a x} / D_{m}$ at constant Pe decreases with the pore diameter (41, 105, and $232 \mathrm{~nm})$. At the same time, the increase of $D_{a x} / D_{m}$ with Pe (indicative for stagnant mobile phase mass transfer resistance and flow heterogeneity) is smaller for the material with wider pores, and the regime in which axial molecular diffusion controls the dispersion $\left(\mathrm{D}_{\mathrm{ax}} / \mathrm{D}_{\mathrm{m}}<1\right)$ can extend to higher Pe. The EDL thickness remained constant in this series of experiments (with $\lambda_{\mathrm{D}}$ around $10 \mathrm{~nm}$, Eq. 3).

The observed behaviour (Figure 5) can be attributed to electroosmotic perfusion. According to classical HPLC theory, diffusion-limited mass transfer inside the stationary phase particles and mechanical dispersion in the surrounding (diffusive-convective) mobile phase become the main sources of band spreading at increasing velocities [82, 109]. It has been shown that with hydraulic flow the holdup due to intraparticle stagnant fluid starts to dominate hydrodynamic dispersion in random packings of porous particles at Pe above about 25 [110]. Electroosmotic intraparticle convection reduces this mass transfer resistance, and wider pores (at constant $\lambda_{\mathrm{D}}$ ) further suppress EDL overlap which, in turn, produces stronger EOF inside the particle. When ultimately the velocity inside a particle equals that outside, there will be no contribution from this mass transfer resistance to the overall separation efficiency and axial dispersion due to the nonuniformity of the flow velocity distribution over the whole column cross-section will be substantially reduced [111]. 


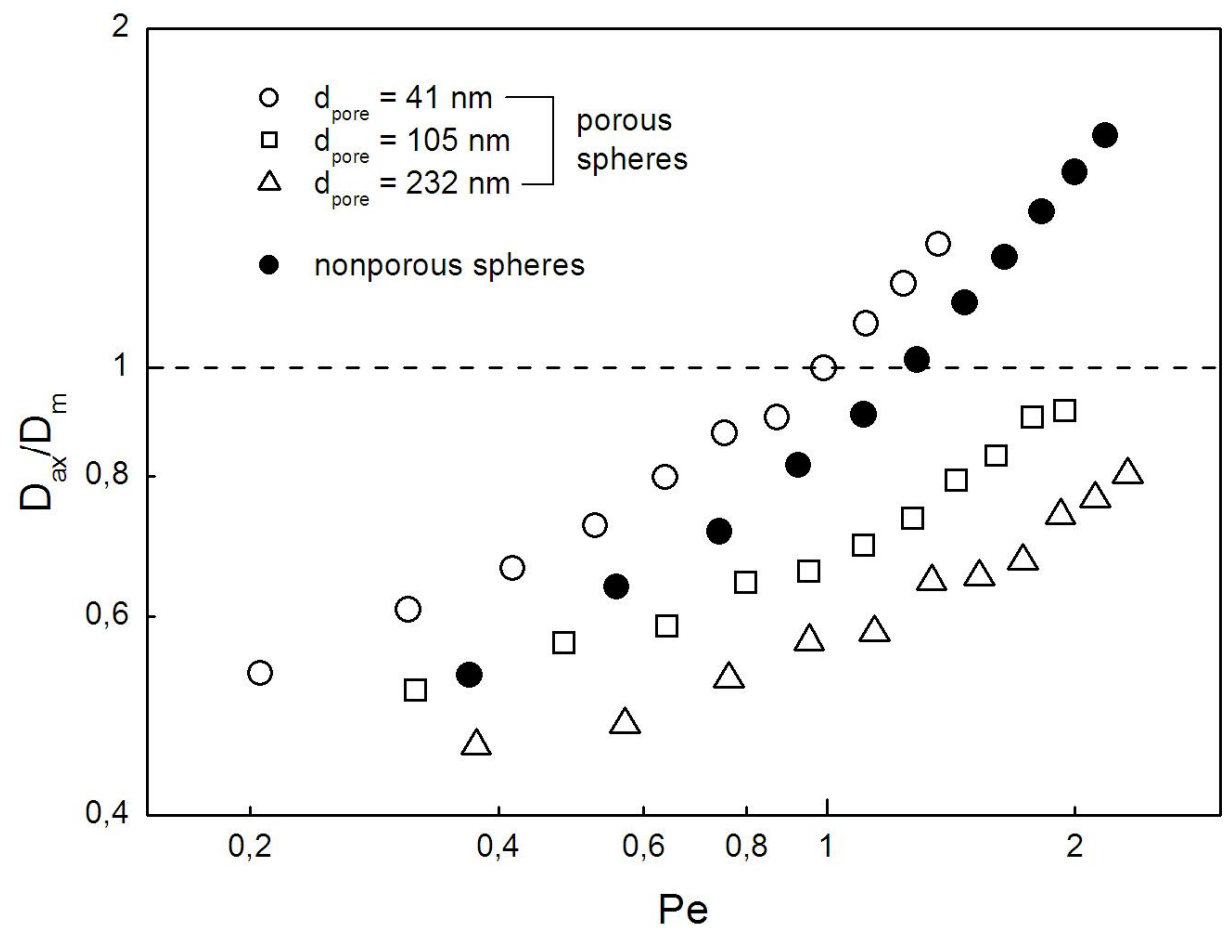

Figure 5. Effect of the mean intraparticle pore size on $D_{a x} / D_{m}$ vs. particle Peclet number $P e=u_{a v} d_{p} / D_{m}$ (EOF) for methylbenzoate. Packed beds: $240 \mathrm{~mm}$ long consisting of the different particles. The mobile phase is acetonitrile-Tris (pH-8.3) 80:20 (v/v) with an effective Tris concentration of $10^{-3} \mathrm{M}$.

It should further be noted that $\mathrm{D}_{\mathrm{ax}} / \mathrm{D}_{\mathrm{m}}$ (for particles with larger pore diameters, 105 and 232 $\mathrm{nm}$ ) is smaller than for the nonporous (or solid) particles. From a standpoint of efficiency the nonporous particles are ideal in that they eliminate the intraparticle stagnant mobile phase [83, $112,113]$. With the nonporous particles, instead the mechanical or eddy dispersion dominates band spreading over a wide range of Pe. From the comparison between these wide-pore and nonporous particles (Figure 5) we can reach the conclusion that a more homogeneous column cross-sectional flow velocity distribution (including the particle-scale) is reached in perfusive electrochromatography. This contrasts with HPLC where nonporous particles result in higher efficiencies than porous ones. It may be explained via an analogy that substantial intraparticle EOF reduces the hydrodynamically effective particle diameter of the wide-pore packings well below that of the nonporous spheres, although (from a physical point of view) both solid and permeable spheres have almost the same mean diameter, as evidenced by Table 2 . 


\subsection{Effect of mobile phase ionic strength on separation efficiency}

As an alternative to the adjustment of mean pore size the mobile phase ionic strength (now at constant pore size) can be varied to systematically tune an intraparticle EDL overlap represented by $r_{\text {pore }} / \lambda_{D}$. The range of values realized for this characteristic ratio in the present work for the different particles and mobile phase concentrations of Tris buffer is summarized in Table 2. Figure 6 demonstrates that dispersion obained with pressure-driven flow is much higher (by up to a factor of 5) than for EOF with any ionic strength through a capillary packed with the same wide-pore particles $\left(\mathrm{d}_{\text {pore }}=105 \mathrm{~nm}\right)$. Due to a dominating effect of intraparticle EDL overlap-suppression at an increasing Tris concentration intraparticle EOF is enhanced. It results in a higher pore-to-interstitial flow ratio. Thus, increasing intraparticle EOF improves flow homogeneity over the column cross-section and decreases mass transfer resistance in the mobile and stationary phases $[54,111]$.

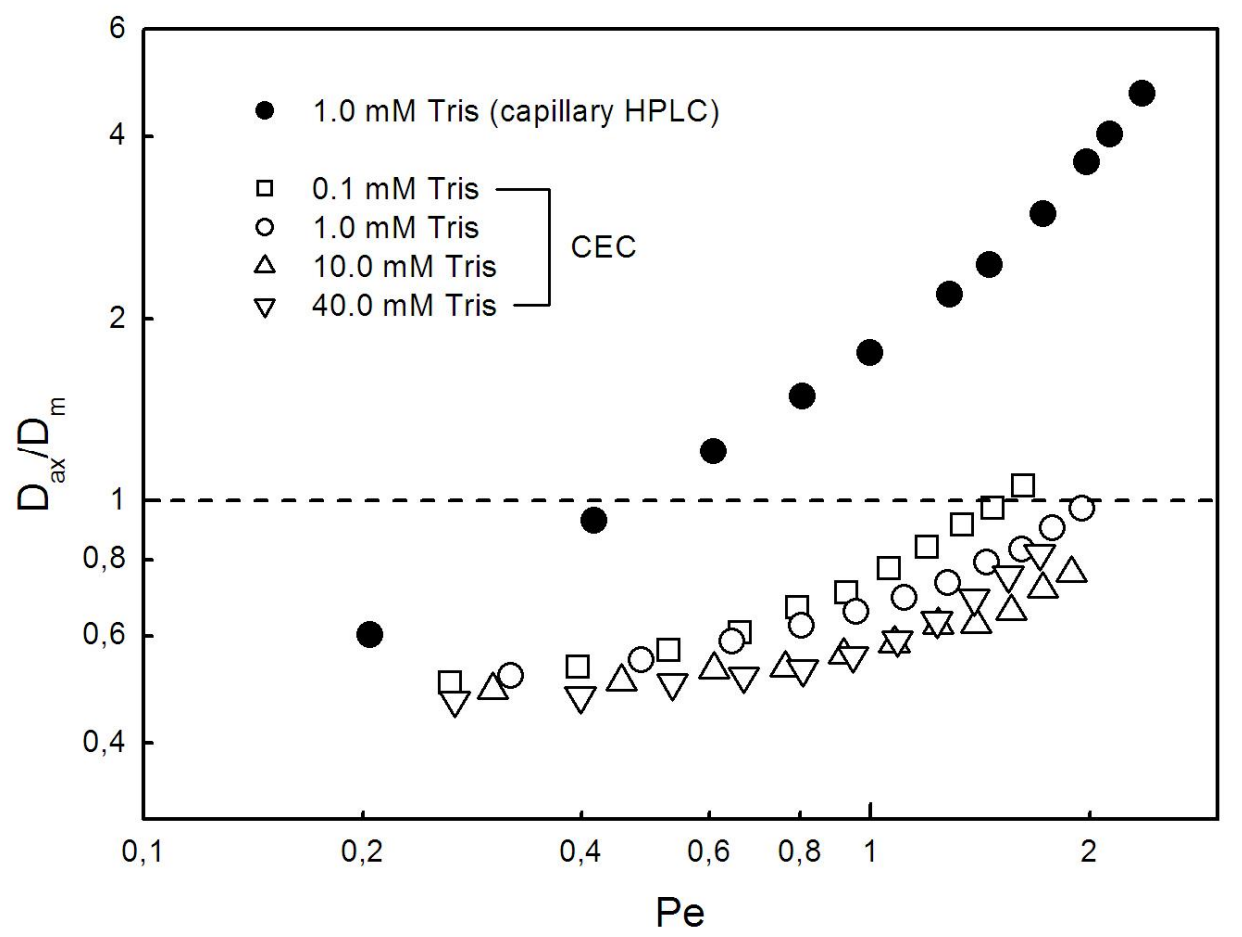

Figure 6. Effect of the Tris buffer concentration on $D_{a x} / D_{m}$ of methylbenzoate vs. $P e=u_{a v} d_{p} / D_{m}$. CEC: $325 \mathrm{~mm}$ long column setup ( $240 \mathrm{~mm}$ bed length), bed of porous C18-silica-particles with $\mathrm{d}_{\mathrm{p}}=2.45 \mu \mathrm{m}$ and $\mathrm{d}_{\mathrm{pore}}=105 \mathrm{~nm}$. Mobile phase: acetonitrile-Tris (pH-8.3) 80:20 (v/v). For capillary HPLC: $150 \mathrm{~mm}$ long x $100 \mu \mathrm{m}$ i.d. column (140 mm bed). The ionic strength of the electrolyte solution corresponds to half of the actual Tris concentration. 
Although qualitatively sound, it becomes difficult to relate this improvement quantitatively to the electroosmotic perfusion mechanism because dispersion coefficients in CEC are acquired inherently over only a limited range of Pe. It results from the relatively small particle diameter $\left(\mathrm{d}_{\mathrm{p}}=2.45 \mu \mathrm{m}\right)$ and limitations in maximum electrical field strength (and current) due to Joule heating [18]. In turn, the results appear insufficient to allow an adequate separation based on the scaling of $\mathrm{D}_{\mathrm{ax}} / \mathrm{D}_{\mathrm{m}}$ with Pe between dispersion processes that originate in the flowing and stagnant zones of a bed [109, 114-116]. For example, it is well-known that for pressure-driven flow stochastic velocity fluctuations between the particles cause mechanical dispersion which grows linearly with $\mathrm{Pe}$, while regions of zero velocity inside a particle and close to its external surface cause non-mechanical contributions growing as $\mathrm{Pe}^{2}$ (holdup dispersion) and $\mathrm{Pe} \cdot \ln (\mathrm{Pe})$ (boundary-layer dispersion), respectively [115].

It needs further studies to resolve a coexistence and relative importance of these contributions in CEC over a wide range of conditions which determine a dependence of $\mathrm{D}_{\mathrm{ax}} / \mathrm{D}_{\mathrm{m}}$ on Pe, like the distribution of pore size and EDL overlap, pore geometry and interconnectivity, the fractal nature and chemical heterogeneity of a surface, dissociation equilibria of both the analyte and surface groups, type of buffer, specific adsorption, charge of analyte, retention mechanism, or the coupling of a nonlinear adsorption with the local electrokinetics. In this respect, selective techniques like spectroscopic imaging methods which allow to focus on particular mechanical or nonmechanical contributions to dispersion are promising approaches in resolving a lumped kinetics and thermodynamics [55, 80, 117-120]. For example, by using quantitative confocal laser scanning microscopy in combination with a microfluidic setup it has been visualized that electrokinetic species transport through a fixed bed of spheres produces, in striking contrast to the symmetric-spherical distributions observed for diffusion-limited operations, pronounced asymmetric intraparticle concentration profiles which is caused by the unidirectional nature of electroosmosis and electrophoresis $[119,120]$. Quantitative image analysis permitted a direct determination of the velocities of intraparticle EOF and electrophoretic migration.

Results based on such experimental approaches corroborate data of the kind shown in Figure 6 in that they provide EOF velocities and electrophoretic mobilities underlying macroscopic behaviour and any improvement in separation efficiency. As also evidenced by Figure 6, the reduction of particle size which accompanies to some extent general miniaturization, together with limitations in maximum velocity (may it be due to hardware considerations, temperature effects, or particle surface properties) places the hydrodynamics in a regime characterized by 
low Reynolds and Peclet numbers where most kinetic processes are diffusion-controlled. For example, in contrast to hydraulic flow the dispersion data acquired with EOF hardly leave the tortuosity-limited regime where molecular diffusion in the tortuous pore space dominates the overall dispersion (Figure $6, D_{a x} / D_{m}<1$ ). The fact that we find an increased dispersion for the highest effective Tris concentration of $40 \mathrm{mM}$ within the series of ionic strengths is explained by the actual power dissipation in the packed bed leading to development of Joule heat [121]. In the absence of Joule heating (and other nonlinear effects) the conductivity of an electrolyte solution is a constant and the current varies linearly with the applied field. As demonstrated in Figure 7, the temperature increase associated with insufficient heat dissipation manifests itself in nonlinear Ohm plots, and deviation from linearity is most pronounced for the highest ionic strength. This effect causes an uncorrected increase of the analytes diffusion coefficient in the bed which, because the dispersion data are acquired in the diffusion-limited regime, is seen in higher dispersivities. The radial temperature profile is usually not strong enough to engender additional significant dispersion due to a macroscopic flow heterogeneity $[122,123]$.

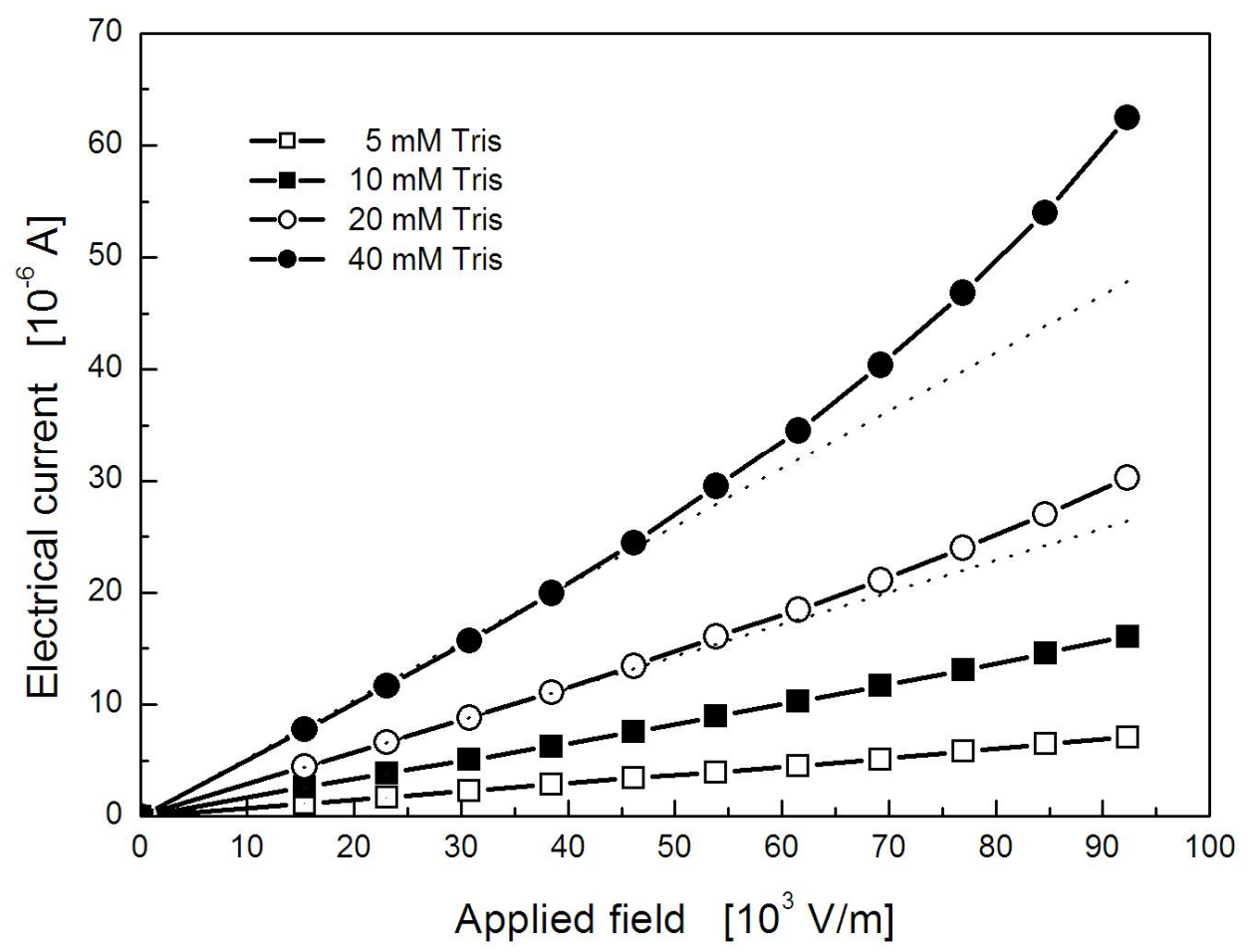

Figure 7. Ohm plots for a $100 \mu \mathrm{m}$ i.d. packed capillary $\left(d_{p}=2.45 \mu \mathrm{m}, d_{\text {pore }}=105 \mathrm{~nm}\right)$. Mobile phase: acetonitrile-Tris $(\mathrm{pH}-8.3)$ 80:20 (v/v) with different effective concentrations. 


\subsection{Effect of ionic strength on average EOF velocity}

In close relation to the dispersion data (Figure 6) we see the associated flow behaviour in Figure 8, i.e., the dependence of the average EOF velocity through the bed on effective Tris concentration in the mobile phase. The actual ionic strength is given by

$$
\mathrm{I}=\frac{1}{2} \sum_{\mathrm{i}} \mathrm{z}_{\mathrm{i}}^{2} \mathrm{c}_{\mathrm{i}, \infty}
$$

and with respect to our work corresponds to half of the Tris concentration. Another important relation is that between the ionic strength and $\zeta$-potential which, for a locally flat surface and (sufficiently) low values of $\zeta$, may be approximated as [124]

$$
\zeta=\frac{\sigma_{\mathrm{s}} \lambda_{\mathrm{D}}}{\varepsilon_{0} \varepsilon_{\mathrm{r}}}=\sigma_{\mathrm{s}}\left(\frac{\mathrm{RT}}{2 \mathrm{~F}^{2} \varepsilon_{0} \varepsilon_{\mathrm{r}} \mathrm{I}}\right)^{1 / 2},
$$

where $\sigma_{\mathrm{s}}$ represents surface charge density insofar as it corresponds with opposite sign to the total (fluid-side) excess charge density up to the surface where the shear plane is located. As seen in Figure 8, the average EOF for nonporous (impermeable and nonconducting) particles reveals a normal electrokinetic behaviour [63], i.e., as the ionic strength increases, the EDL is compressed which results in a reduced shear plane $(\zeta)$ potential at the solid-liquid interface (Eq. 10) and causes the continuously decreasing EOF velocities. The EDL thickness remained small with respect to a particle radius $\left(\mathrm{r}_{\mathrm{s}}\right)$ over the whole range of buffer concentrations $(38<$ $\mathrm{r}_{\mathrm{s}} / \lambda_{\mathrm{D}}<766$ ). Thus, EDL overlap in the interparticle pore space (although already moderate at lower ionic strength) was not significant enough to dominate the electrokinetic behaviour and lead to an intermediate increase of the EOF velocity with ionic strength. The behaviour of the solid particles thus can be understood in view of Eq. 10.

This situation is different for the porous (permeable and conducting) particles. Before also in these cases (cf. Figure 8) the velocity finally decreases at increasing ionic strength, it displays pronounced maxima. This behaviour is due to the significant suppression of intraparticle EDL overlap (leading to an increase of intraparticle EOF) which causes the average EOF through a bed to increase intermediately. The dependence of average EOF velocity with porous particles on ionic strength (Figure 8) in principle is a consequence of the following contributions [125128], i) usual EDL behaviour at the external particle surface leading to a decrease of velocity 
at increasing ionic strength, ii) the generation of intraparticle EOF which increases with ionic strength, and iii) particle porosity (independent of ionic strength). The last contribution results from the fact that conducting electrolyte in the particle introduces a normal component to the electrical field at its outer surface. This reduces a fields tangential component, but because the latter determines velocity at the particles external surface it is expected to decrease compared to a solid particle, the more as porosity increases [126]. While the first contribution dominates overall velocities at higher ionic strengths (above $1 \times 10^{-2} \mathrm{M}$ Tris, see Figure 8 ), the perfusive EOF is responsible for an increasing velocity at the lower ionic strengths. A similar behaviour has been observed for porous particles when subjected to an electrophoresis experiment [128]. Based on measured porosimetry data for porous particles already simple cylindrical capillary models of a packed bed, together with the approximate expressions after Rice and Whitehead [35] for single-pore EOF, have successfully explained relative magnitudes of intraparticle and interparticle EOF depending on EDL overlap inside the particles [52, 129].

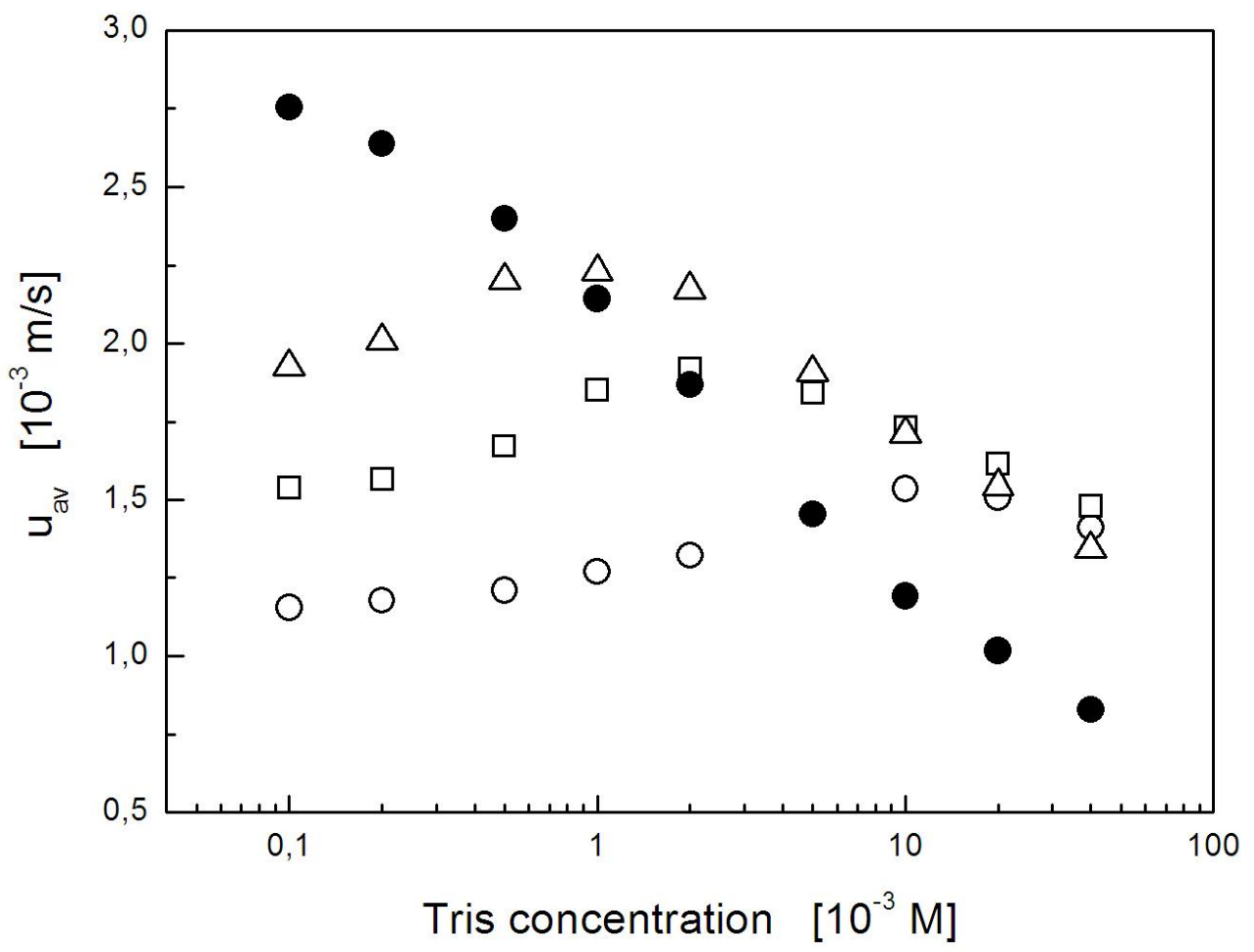

Figure 8. Effect of mobile phase Tris concentration on the average EOF through packed beds of the C18-silica particles (applied voltage: $20 \mathrm{kV}$ ). Nonporous particles (, ), porous particles: $\mathrm{d}_{\text {pore }}=41 \mathrm{~nm}$ $(-), d_{\text {pore }}=105 \mathrm{~nm}(")$, and $\mathrm{d}_{\text {pore }}=232 \mathrm{~nm}(8)$. 


\section{Conclusions}

Our data demonstrate that a tremendous performance advantage of CEC over capillary HPLC lies in the different dimension and experimental realization of a substantially perfusive flow field. Development in CEC particle technology therefore should focus on the minimum mean pore size of the throughpore network which allows a still significant intraparticle EOF at decent mobile phase ionic strength, while keeping the surface-to-volume ratio of a medium high enough for separations of complex mixtures (gigapores, as with pressure-driven flow, are not required in an electroosmotic perfusion). With CEC in perfusive mode the fluid in most of the pore space is no longer stagnant and the system has the characteristics of a bed composed of much smaller, essentially nonporous particles being ideal from the standpoint of efficiency. CEC can then easily be realized in effective nanoparticle dimension, but by employing porous supports of micrometer-size. This, in turn, leaves molecular diffusion as an ultimate limitation to performance (as shown in this work). Thus, the perfusive EOF field in fixed beds of porous particles translates to even higher separation efficiency than currently achieved in CEC using narrow-pore supports or nonporous particles, an increased mass sensitivity in on-line coupling schemes like nano-ESI-MS, and - due to the higher hydraulic permeability of beds of micronsized particles - the possibility of implementing pressurized CEC in view of a higher analysis speed, flow stability and reproducibility, but without much increase in dispersion. Further, the practical problems associated with direct nanoparticle packing like clogging or the generation of instable beds are avoided.

\section{Acknowledgements}

We are grateful to Dieter Lubda from Merck KGaA (Darmstadt, Germany) for the preparation of the C18-silica particle research samples. We further acknowledge financial support by the Landesgraduiertenförderung Sachsen-Anhalt (Germany) to Guofang Chen. Martin Pačes was supported by the Czech grant agency under grant 104/02/0339, and we are also grateful to the Deutsche Forschungsgemeinschaft for financial support of this work (grant SE 586/7-2). 


\section{List of symbols:}

\begin{tabular}{|l|l|l|}
\hline$c_{i, \infty}$ & {$\left[\mathrm{mol} \mathrm{l}^{-1}\right]$} & equilibrium concentration of type i ions beyond the EDL \\
\hline$d_{c}$ & {$[\mathrm{~m}]$} & column inner diameter \\
\hline$d_{\text {pore }}$ & {$[\mathrm{m}]$} & mean intraparticle pore diameter \\
\hline$d_{p}$ & {$[\mathrm{~m}]$} & mean particle diameter \\
\hline$D_{a x}$ & {$\left[\mathrm{~m}^{2} \mathrm{~s}^{-1}\right]$} & axial dispersion coefficient \\
\hline$D_{m}$ & {$\left[\mathrm{~m}^{2} \mathrm{~s}^{-1}\right]$} & free molecular diffusion coefficient of analyte in mobile phase \\
\hline E & {$\left[\mathrm{V} \mathrm{m}^{-1}\right]$} & electrical field strength \\
\hline $\mathrm{F}$ & {$\left[\mathrm{C} \mathrm{mol}^{-1}\right]$} & Faraday constant \\
\hline $\mathrm{H}$ & {$\left[\mathrm{m}^{-1}\right.$} & height equivalent to a theoretical plate \\
\hline $\mathrm{I}$ & {$\left[\mathrm{mol} \mathrm{l}^{-1}\right]$} & mobile phase ionic strength \\
\hline $\mathrm{L}_{\text {bed }}$ & {$\left[\mathrm{m}^{-1}\right.$} & length of the packed bed \\
\hline $\mathrm{N}$ & {$[-]$} & plate number \\
\hline Pe & {$[-]$} & particle Peclet number \\
\hline $\mathrm{R}$ & {$\left[\mathrm{J} \mathrm{mol}^{-1} \mathrm{~K}^{-1}\right]$} & gas constant \\
\hline $\mathrm{u}_{\mathrm{av}}$ & {$\left[\mathrm{m} \mathrm{s}^{-1}\right]$} & average mobile phase velocity through the packed column \\
\hline $\mathrm{u}_{\mathrm{p}}$ & {$\left[\mathrm{m} \mathrm{s}^{-1}\right]$} & local EOF (slip) velocity close to a particles surface \\
\hline $\mathrm{V}_{\mathrm{c}}$ & {$\left[\mathrm{m}^{3}\right]$} & total column volumn \\
\hline $\mathrm{V}_{\text {inter }}$ & {$\left[\mathrm{m}^{3}\right]$} & volume of the interparticle pore space \\
\hline
\end{tabular}

\begin{tabular}{|l|l|l|}
\hline$\varepsilon_{0}$ & {$\left[\mathrm{C}^{2} \mathrm{~J}^{-1}\right]$} & permittivity of vacuum \\
\hline$\varepsilon_{\text {intra }}$ & {$[-]$} & intraparticle porosity \\
\hline$\varepsilon_{\mathrm{r}}$ & {$[-]$} & relative permittivity of the electrolyte solution \\
\hline$\varepsilon_{\text {bed }}$ & {$[-]$} & total porosity of packed column \\
\hline$\eta_{\mathrm{f}}$ & {$[\mathrm{Pa} \mathrm{s}]$} & dynamic viscosity of the mobile phase \\
\hline$\lambda_{\mathrm{D}}$ & {$[\mathrm{m}]$} & Debye screening length \\
\hline$\zeta_{\mathrm{p}}$ & {$[\mathrm{V}]$} & zeta-potential at a particle surface \\
\hline$\zeta_{\mathrm{w}}$ & {$[\mathrm{V}]$} & zeta-potential at the capillary inner wall \\
\hline
\end{tabular}




\section{References}

[1] Cs. Horváth, B. A. Preiss, S. R. Lipsky, Anal. Chem. 1967, 39, 1422.

[2] Cs. Horváth, S. R. Lipsky, Anal. Chem. 1969, 41, 1227.

[3] R. P. W. Scott, P. Kucera, J. Chromatogr. 1976, 125, 251.

[4] D. Ishii, K. Asai, K. Hibi, T. Jonokuchi, M. Nagaya, J. Chromatogr. 1977, 144, 157.

[5] D. Ishii (Ed.), Introduction to Microscale High-Performance Liquid Chromatography, VCH, Weinheim 1988.

[6] J. P. C. Vissers, H. A. Claessens, C. A. Cramers, J. Chromatogr. A 1997, 779, 1.

[7] J. P. C. Vissers, J. Chromatogr. A 1999, 856, 117.

[8] J. Abian, A. J. Oosterkamp, E. Gelpi, J. Mass Spectrom. 1999, 34, 244.

[9] G. P. Rozing, M. Serwe, H.-G. Weissgerber, B. Glatz, Am. Lab. 2001, 33, 26.

[10] M. Szumski, B. Buszewski, Crit. Rev. Anal. Chem. 2002, 32, 1.

[11] E. Rapp, U. Tallarek, J. Sep. Sci. 2003, 26, 453.

[12] R. F. Probstein, R. E. Hicks, Science 1993, 260, 498.

[13] J. E. Sauer, E. J. Davis, Environ. Sci. Technol. 1994, 28, 737.

[14] M. M. Dittmann, K. Wienand, F. Bek, G. P. Rozing, $L C \bullet G C$ 1995, 13, 800.

[15] S. V. Ho, P. W. Sheridan, C. J. Athmer, M. A. Heitkamp, J. M. Brackin, D. Weber, P. H. Brodsky, Environ. Sci. Technol. 1995, 29, 2528.

[16] T. Tsuda (Ed.), Electric Field Applications in Chromatography, Industrial and Chemical Processes, VCH, Weinheim 1995.

[17] Y. B. Acar, E. E. Ozsu, A. N. Alshawabkeh, M. F. Rabbi, R. J. Gale, CHEMTECH 1996, $26,40$.

[18] A. L. Crego, A. González, M. L. Marina, Crit. Rev. Anal. Chem. 1996, 26, 261.

[19] T. F. Coletta, C. J. Brunell, D. K. Ryan, H. I. Inyang, J. Environ. Eng. 1997, 123, 1227.

[20] C. Fujimoto, Trends Anal. Chem. 1999, 18, 291.

[21] L. A. Colón, G. Burgos, T. D. Maloney, J. M. Cintrón, R. L. Rodríguez, Electrophoresis 2000, 21, 3965 .

[22] U. Pyell, J. Chromatogr. A 2000, 892, 257.

[23] Q. L. Tang, M. L. Lee, Trends Anal. Chem. 2000, 19, 648.

[24] N. A. Polson, M. A. Hayes, Anal. Chem. 2001, 73, 312A.

[25] Z. Deyl, F. Svec (Eds.), Capillary Electrochromatography, Journal of Chromatography Library, vol. 62, Elsevier, Amsterdam 2001.

[26] A. S. Rathore, Electrophoresis 2002, 23, 3827.

[27] K. Mistry, I. Krull, N. Grinberg, J. Sep. Sci. 2002, 25, 935.

[28] A. V. Delgado (Ed.), Interfacial Electrokinetics and Electrophoresis, Marcel Dekker, New York 2002.

[29] T. Tsuda, Anal. Chem. 1987, 59, 521.

[30] V. Pretorius, B. J. Hopkins, J. D. Schieke, J. Chromatogr. 1974, 99, 23.

[31] J. W. Jorgenson, K. D. Lukacs, J. Chromatogr. 1981, 218, 209.

[32] J. H. Knox, I. H. Grant, Chromatographia 1987, 24, 135.

[33] J. H. Knox, Chromatographia 1988, 26, 329.

[34] J. H. Knox, I. H. Grant, Chromatographia 1991, 32, 317. 
[35] C. L. Rice, R. Whitehead, J. Phys. Chem. 1965, 69, 4017.

[36] R. J. Gross, J. F. Osterle, J. Chem. Phys. 1968, 48, 228.

[37] K.-L. K. Liu, K. L. Davis, M. D. Morris, Anal. Chem. 1994, 66, 3744.

[38] S. Arulanandam, D. Q. Li, Colloids Surf. A 2000, 161, 89.

[39] R. F. Probstein, Physicochemical Hydrodynamics, John Wiley \& Sons, New York 1994.

[40] P. H. Paul, M. G. Garguilo, D. J. Rakestraw, Anal. Chem. 1998, 70, 2459.

[41] U. Tallarek, E. Rapp, T. Scheenen, E. Bayer, H. Van As, Anal. Chem. 2000, 72, 2292.

[42] K. K. Unger, S. Lüdtke, M. Grün, LC-GC Int. 1999, 12, 870.

[43] K. K. Unger, D. Kumar, M. Grün, D. Büchel, S. Lüdtke, Th. Adam, K. Schumacher, S. Renker, J. Chromatogr. A 2000, 892, 47.

[44] T. Sakaki, S. Kitagawa, T. Tsuda, Electrophoresis 2000, 21, 3088.

[45] J. P. Kutter, S. C. Jacobson, N. Matsubara, J. M. Ramsey, Anal. Chem. 1998, 70, 3291.

[46] C. Ericson, J. Holm, T. Ericson, S. Hjerten, Anal. Chem. 2000, 72, 81.

[47] R. D. Oleschuk, L. L. Schultz-Lockyear, Y. B. Ning, D. J. Harrison, Anal. Chem. 2000, 72, 585.

[48] B. E. Slentz, N. A. Penner, E. Lugowska, F. E. Regnier, Electrophoresis 2001, 22, 3763.

[49] D. J. Throckmorton, T. J. Shepodd, A. K. Singh, Anal. Chem. 2002, 74, 784.

[50] R. Stol, W. Th. Kok, H. Poppe, J. Chromatogr. A 1999, 853, 45.

[51] E. Wen, R. Asiaie, Cs. Horváth, J. Chromatogr. A 1999, 855, 349.

[52] P. T. Vallano, V. T. Remcho, Anal. Chem. 2000, 72, 4255.

[53] U. Tallarek, E. Rapp, H. Van As, E. Bayer, Angew. Chem. Int. Ed. 2001, 40, 1684.

[54] R. Stol, H. Poppe, W. Th. Kok, Anal. Chem. 2001, 73, 3332.

[55] U. Tallarek, E. Rapp, A. Seidel-Morgenstern, H. Van As, J. Phys. Chem. B 2002, 106, 12709.

[56] R. Xiang, Cs. Horváth, Anal. Chem. 2002, 74, 762.

[57] S. R. Dziennik, E. B. Belcher, G. A. Barker, M. J. DeBergalis, S. E. Fernandez, A. M. Lenhoff, Proc. Natl. Acad. Sci. U.S.A. 2003, 100, 420.

[58] A. S. Rathore, Cs. Horváth, J. Chromatogr. A 1997, 781, 185.

[59] M. von Smoluchowski, in I. Grätz (Ed.), Handbuch der Elektrizität und des Magnetismus, Barth, Leipizig 1921, pp. 366-428.

[60] J. Th. G. Overbeek, in H. R. Kruyt (Ed.), Colloid Science, Elsevier, New York 1952, pp. 194-244.

[61] R. W. O'Brien, J. Colloid Interface Sci. 1986, 110, 477.

[62] J. Th. G. Overbeek, P. W. O. Wijga, Rec. Trav. Chim. 1946, 65, 556.

[63] J. Lyklema, Fundamentals of Interface and Colloid Science. Vol. II: Solid-Liquid Interfaces; Academic Press, London 1995.

[64] L. A. Colón, K. J. Reynolds, R. Alicea-Maldonado, A. M. Fermier, Electrophoresis 1997, 18, 2162.

[65] O. Bey, G. Eigenberger, Chem. Eng. Sci. 1997, 52, 1365.

[66] M. Giese, K. Rottschäfer, D. Vortmeyer, AIChE J. 1998, 44, 484.

[67] A. J. Sederman, P. Alexander, L. F. Gladden, Powder Technol. 2001, 117, 255.

[68] J. C. Park, K. Raghavan, S. J. Gibbs, J. Chromatogr. A 2002, 945, 65.

[69] T. C. Hsiang, H. W. Haynes, Jr., Chem. Eng. Sci. 1977, 32, 678.

[70] H. Martin, Chem. Eng. Sci. 1978, 33, 913.

[71] R. G. Carbonell, Chem. Eng. Sci. 1980, 35, 1347. 
[72] E. Tsotsas, E.-U. Schlünder, Chem. Eng. Process. 1988, 24, 15.

[73] B.-J. Ahn, A. Zoulalian, J. M. Smith, AIChE J. 1986, 32, 170.

[74] E. Tsotsas, Über die Wärme- und Stoffübertragung in durchströmten Festbetten, Fortschritt-Berichte VDI, Reihe 3, Nr. 223, VDI-Verlag, Düsseldorf 1990.

[75] A. I. Liapis, B. A. Grimes, J. Chromatogr. A 2000, 877, 181.

[76] G. Neale, N. Epstein, W. Nader, Chem. Eng. Sci. 1973, 28, 1865.

[77] G. Choudhary, Cs. Horváth, J. Chromatogr. A 1997, 781, 161.

[78] A. S. Rathore, E. Wen, Cs. Horváth, Anal. Chem. 1999, 71, 2633.

[79] Y. Liu, D. J. Pietrzyk, Anal. Chem. 2000, 72, 5930.

[80] U. Tallarek, T. W. J. Scheenen, H. Van As, J. Phys. Chem. B 2001, 105, 8591.

[81] J. J. Van Deemter, F. J. Zuiderweg, A. Klinkenberg, Chem. Eng. Sci., 1956, 5, 271.

[82] J. C. Giddings, Dynamics of Chromatography. Part I: Principles and Theory, Marcel Dekker, New York 1965

[83] B. J. Kennedy, J. H. Knox, J. Chromatogr. Sci. 1985, 10, 549.

[84] M. E. Van Kreveld, N. Van den Hoed, J. Chromatogr. 1978, 149, 71.

[85] N. B. Afeyan, N. F. Gordon, I. Mazsaroff, L. Varady, S. P. Fulton, Y. B. Yang, F. E. Regnier, J. Chromatogr. 1990, 519, 1.

[86] A. E. Rodrigues, Z. P. Lu, J. M. Loureiro, Chem. Eng. Sci. 1991, 46, 2765.

[87] A. I. Liapis, M. A. McCoy, J. Chromatogr. 1992, 599, 87.

[88] A. E. Rodrigues, J. C. Lopes, Z. P. Lu, J. M. Loureiro, M. M. Dias, J. Chromatogr. 1992, 590, 93.

[89] G. Carta, M. E. Gregory, D. J. Kirwan, H. A. Massaldi, Sep. Technol. 1992, 2, 62.

[90] D. D. Frey, E. Schweinheim, Cs. Horváth, Biotechnol. Prog. 1993, 9, 273.

[91] P.-E. Gustavsson, P.-O. Larsson, J. Chromatogr. A 1996, 734, 231.

[92] M. McCoy, K. Kalghatgi, F. E. Regnier, N. Afeyan, J. Chromatogr. A 1996, 743, 221.

[93] D. C. Nash, H. A. Chase, J. Chromatogr. A 1998, 807, 185.

[94] J. F. Pfeiffer, J. C. Chen, J. T. Hsu, AIChE J. 1996, 42, 932.

[95] U. Tallarek, F. J. Vergeldt, H. Van As, J. Phys. Chem. B 1999, 103, 7654.

[96] D. H. Reeder, A. M. Clausen, M. J. Annen, P. W. Carr, M. C. Flickinger, A. V. McCormick, J. Colloid Interface Sci. 1996, 184, 328.

[97] D. Whitney, M. McCoy, N. Gordon, N. Afeyan, J. Chromatogr. A 1998, 807, 165.

[98] E. Venema, J. C. Kraak, H. Poppe, R. Tijssen, J. Chromatogr. A 1999, 837, 3.

[99] P. T. Vallano, V. T. Remcho, J. Phys. Chem. B 2001, 105, 3223.

[100] U. D. Neue, HPLC Columns: Theory, Technology, and Practice, Wiley-VCH, New York 1997.

[101] A. Banholczer, U. Pyell, J. Chromatogr. A 2000, 869, 363.

[102] G. Guiochon, S. G. Shirazi, A. M. Katti, Fundamentals of Preparative and Nonlinear Chromatography, Academic Press, Boston 1994.

[103] K. D. Cole, H. Cabezas, Jr., J. Chromatogr. A 1997, 760, 259.

[104] C. Keim, M. Ladisch, Biotechnol. Bioeng. 2000, 70, 72.

[105] C. M. Tellez, K. D. Cole, Electrophoresis 2000, 21, 1001.

[106] G. Yin, Z. Liu, R. Zhou, J. Zhan, J. Wang, N. J. Yuan, J. Chromatogr. A 2001, 918, 393.

[107] M. Pačes, J. Kosek, M. Marek, U. Tallarek, A. Seidel-Morgenstern, Electrophoresis 2003, $24,380$. 
[108] M. Pačes, U. Tallarek, A. Seidel-Morgenstern, J. Kosek, M. Marek, in Proc. of the $1^{\text {st }}$ Int. Symp. on Process Intensification and Miniaturization (Eds: G. Akay, M. Dogru), University of Newcastle 2003.

[109] J. H. Knox, J. Chromatogr. A 1999, 831, 3.

[110] D. Kandhai, D. Hlushkou, A. G. Hoekstra, P. M. A. Sloot, H. Van As, U. Tallarek, Phys. Rev. Lett. 2002, 88 , art. no. 234501.

[111] H. Poppe, R. Stol, W. Th. Kok, J. Chromatogr. A 2002, 965, 75.

[112] Y. L. Yang, M. L. Lee, J. Microcol. Sep. 1999, 11, 131.

[113] S. R. Witowski, R. T. Kennedy, J. Microcol. Sep. 1999, 11, 723.

[114] D. L. Koch, J. F. Brady, J. Fluid Mech. 1985, 154, 399.

[115] M. Sahimi, Flow and Transport in Porous Media and Fractured Rock, VCH, Weinheim 1995.

[116] U. Tallarek, E. Bayer, G. Guiochon, J. Am. Chem. Soc. 1998, 120, 1494.

[117] U. Tallarek, T. W. J. Scheenen, P. A. de Jager, H. Van As, Magn. Reson. Imag. 2001, 19, 453.

[118] B. R. Locke, M. Acton, S. J. Gibbs, Langmuir 2001, 17, 6771.

[119] U. Tallarek, E. Rapp, H. Sann, U. Reichl, A. Seidel-Morgenstern, Langmuir 2003, $19,4527$.

[120] U. Tallarek, M. Pačes, E. Rapp, Electrophoresis (in press).

[121] A. S. Rathore, K. J. Reynolds, L. A. Colón, Electrophoresis 2002, 23, 2918.

[122] J. H. Knox, K. A. McCormack, Chromatographia 1994, 38, 207.

[123] K.-L. K. Liu, K. L. Davis, M. D. Morris, M. D. Anal. Chem. 1994, 66, 3744.

[124] A. W. Adamson, A. P. Gast, Physical Chemistry of Surfaces, John Wiley \& Sons, New York 1997.

[125] S. Levine, G. H. Neale, J. Colloid Interface Sci. 1974, 47, 520.

[126] N. P. Miller, J. C. Berg, R. W. O'Brien, J. Colloid Interface Sci. 1992, 153, 237.

[127] N. P. Miller, J. C. Berg, J. Colloid Interface Sci. 1993, 159, 253.

[128] G. Chen, U. Tallarek, Langmuir (in press).

[129] R. Stol, H. Poppe, W. Th. Kok, J. Chromatogr. A 2000, 887, 199. 